\title{
Abkürzungen und Zitation
}

Folgende Abkürzungen finden Verwendung:

$\begin{array}{ll}\text { GMD } & \text { Das griechische Musikdrama } \\ \text { ST } & \text { Socrates und die Tragoedie } \\ \text { DW } & \text { Die dionysische Weltanschaung } \\ \text { GG } & \text { Die Geburt des tragischen Gedankens } \\ \text { SGT } & \text { Sokrates und die griechische Tragoedie } \\ \text { GT } & \text { Die Geburt der Tragödie } \\ \text { ZBA } & \text { Ueber die Zukunft unserer Bildungsanstalten } \\ \text { FV } & \text { Fünf Vorreden zu fünf ungeschriebenen Büchern } \\ \text { PW } & \text { Ueber das Pathos der Wahrheit } \\ \text { GS } & \text { Der griechische Staat } \\ \text { HW } & \text { Homer's Wettkampf } \\ \text { WL } & \text { Ueber Wahrheit und Lüge im aussermoralischen Sinne } \\ \text { PhZG } & \text { Die Philosophie im tragischen Zeitalter der Griechen } \\ \text { UB II (HL) } & \text { Vom Nutzen und Nachtheil der Historie für das Leben } \\ \text { UB III (SE) } & \text { Schopenhauer als Erzieher } \\ \text { UB IV } & \text { Richard Wagner in Bayreuth }\end{array}$

Die Arbeiten Nietzsches werden durchweg nach der Kritischen Studienausgabe (KSA), herausgegeben von G. Colli und M. Montinari (München/Berlin/New York 19882), zitiert.

(Sonstige Ausgaben werden nur selten verwendet: F. Nietzsche, Jugendschriften, München 1923, Musarion Verlag; und F. Nietzsche, Die Unschuld des Werdens, Stuttgart 1978, Alfred Kröner Verlag.)

Die Zitate aus der KSA werden unter Angabe von Kurztitel (Sigle), Seite(n) und Zeile(n) angeführt. Beispielsweise: GT: 29, 18-22 heiBt: Die Geburt der Tragödie, Seite 29, die Zeilen 18 bis 22.

Die übergroße Mehrzahl der Zitate ist dem ersten Band der Kritischen Studienausgabe entnommen. Dieser Band umfaBt ja das Frühwerk, weshalb die Angabe des Bandes in diesen Fällen fehlt. In den andern Fällen verweist die Zahl vor dem Kolon auf den Band (z. B: 6: 316, 1 - 321, 6 heißt: Band 6, Seite 316, Zeile 1 bis Seite 321, Zeile 6).

Allerdings wird es sich in der Regel um Stellen aus dem frühen Nachlaß (1869-1874) handeln, der im siebten Band der KSA erschlossen ist. In diesen Fällen geschieht die Angabe zuerst unter den von Colli-Montinari verwendeten Siglen, nach einem Semikolon folgt von neuem die Angabe des Bandes, sodann aber die Angabe von Seite(n) und Zeile(n) (z. B.: 7: 30 [8]; 7: 734, 4-12). In den letzteren Fällen handelt es sich meist um einen Ausschnitt aus der betreffenden Aufzeichnung.

Die Verweise auf den Kommentarband von Colli-Montinari vermerken nur Band und Seitenzahl (z.B. 14: 67).

Hervorhebungen, die von mir vorgenommen wurden, sind ausdrücklich als solche verzeichnet. Am sonsten gehören sie dem Originaltext an. 
